\title{
Accidental dural puncture in obstetric patients and long term symptoms
}

\author{
C MacArthur, M Lewis, E G Knox
}

\begin{abstract}
Objective-To examine the association between accidental dural puncture and long term headache and related symptoms.

Design-Postal questionnaire survey to elucidate new symptoms occurring after childbirth, and linking of these to data in obstetric and anaesthetic case notes. Women were surveyed between 13 months and nine years after delivery.

Setting-Birmingham Maternity Hospital.

Subjects -4700 women who had delivered their most recent baby under epidural anaesthesia, 74 of whom had suffered an accidental dural puncture.

Main outcome measures-Frequencies of new headache or migraine or neck ache starting within three months after childbirth and lasting over six weeks.

Results-Among the 74 women who had had an accidental dural puncture there were $17(23 \%)$ who reported one or more of the above symptoms. By comparison, among those who had had an epidural anaesthetic but no recorded puncture, only 329 $(7 \cdot 1 \%)$ reported these symptoms. The duration of the headache or migraine or neck ache in the dural tap group ranged from nine weeks to over eight years. Ten of these women reported still unresolved symptoms.
\end{abstract}

Conclusions-Conclusions on causality were tentative. Most women would remember a dural tap, and this might influence their reporting of subsequent symptoms attributable to the event. In addition, detailed characterisation of the symptoms was not available. Nevertheless, the findings provide a clear indication of the need for further study of the possible long term sequelae of accidental dural puncture.

\section{Introduction}

Postdural puncture headache has long been recognised as a complication of both spinal and epidural anaesthesia and has been recorded in several studies of patients having an obstetric epidural anaesthetic. ${ }^{1-4}$ Accidental dural puncture is thought to occur in around $1 \%$ of cases $^{56}$ and is associated with the experience of the anaesthetist, the needle size, and the method used for identifying the epidural space. ${ }^{1-37}$

Postdural puncture headache is generally distinctive, postural, and frontal; is relieved when the patient is supine; frequently affects neck and shoulders; and may be accompanied by auditory or visual symptoms or nausea. ${ }^{8}$ Symptoms do not always occur after accidental dural puncture, but when they do they are usually reported within the first two days. ${ }^{910}$ Crawford found that the headache could last for up to six days, with some residual "muzziness" for a further day or two. ${ }^{1}$ However, patients have not been routinely followed up for long term symptoms after discharge from hospital, although there have been one or two case reports. ${ }^{11} 12$

We have reported an association between epidural anaesthesia and a range of long term symptoms, including frequent headache, ${ }^{1314}$ but without specific reference to dural puncture. Those findings were based on symptoms reported by women after childbirth and linked to their obstetric records. We subsequently linked additional information from the anaesthetic records of the same women and in this paper describe the long term symptoms reported by those who had had an accidental dural puncture.

\section{Subjects and methods}

The method relating to the first part of this investigation has been described. ${ }^{13} 15$ Briefly, all women who had delivered in Birmingham Maternity Hospital between 1978 and 1985 were identified $(n=30096)$ and their delivery related characteristics obtained from the computerised records. The women were sent postal questionnaires asking about their experience of a list of 25 symptoms starting after the birth of their most recent child, and there were 11701 replies. We contacted women using addresses given at the time of birth, as the local family health services authority refused access to their records for tracing. Using post office and electoral register sources, we estimated a response rate of $78 \%$ from among those who received their questionnaires. ${ }^{13} 15$ The questionnaires were sent in January 1987, 13 months to nine years after the delivery, and allowed the reporting of long term problems. Only accurately dated new symptoms starting within three months of the delivery and lasting over six weeks were included.

Of the 11701 respondents, 4766 had had epidural anaesthesia either for labour or for caesarean section. The obstetric case notes merely recorded the types of analgesia and anaesthesia used. The study hospital, however, kept a separate set of anaesthetic notes for women who had had epidural anaesthesia which recorded technical details of each anaesthetic together with the results of daily inpatient follow up by the anaesthetic staff. These case notes systematically recorded accidental dural puncture, and it was the practice in the hospital to inform the woman if this complication had occurred.

The anaesthetic records were linked to the main obstetric record and to the questionnaire information for each woman. Sixty six anaesthetic records could not be located, so that the information in this report relates to the 4700 cases with fully linked anaesthetic, obstetric, and questionnaire data.

\section{Results}

\section{ACCIDENTAL DURAL PUNCTURE}

Among the 4700 women given an epidural anaes- 
thetic, $74(1 \cdot 6 \%)$ sustained an accidental dural puncture. As in other series, there were statistically significant associations between the occurrence of accidental puncture and the total number of epidural anaesthetics performed by the anaesthetist and the method used for identifying the epidural space. The greatest proportion of taps occurred with use of the MacIntosh balloon technique (table I).

\section{LONG TERM SYMPTOMS}

Information on the occurrence and duration of longer term symptoms was available from the postal questionnaires returned by the women. The 74 who had suffered an accidental dural puncture were compared for all 25 symptoms listed on the questionnaire with those who had had an epidural anaesthetic but not suffered a dural puncture. Table II shows the statistically significant associations, together with the symptom rates in women who had not received an epidural anaesthetic. Frequent long term headache or migraine and neck ache were reported significantly more often by women who had had a dural puncture than in the other groups. Shoulder ache was also more frequent, but not significantly so $\left(\chi^{2}=3.33\right)$, and all those reporting shoulder ache after dural puncture had had headache as well. None of the other symptoms on the questionnaire were significantly associated with accidental dural puncture. Visual disturbances and auditory symptoms are shown in table I because they have been recorded as short term effects of dural puncture. ${ }^{16}$ Numbers, however, were too small to warrant comment.

Some women had had long term headache as well as neck ache, so that a total of 17 women reported one or both of these symptoms (table II). Our definition of relevant long term symptoms used strict inclusion criteria (accurately dated symptoms not previously experienced, lasting over six weeks), and three of the four women defined as having long term neck ache but not meeting the criteria for headache had nevertheless mentioned headache. One woman could not recall the duration of her headaches, one reported a headache lasting only three weeks, and another had experienced headaches before. The only woman who had not

TABLE I-Characteristics associated with accidental dural puncture

\begin{tabular}{lrr}
\hline & $\begin{array}{c}\text { No (\%) of cases } \\
\text { of dural puncture }\end{array}$ & $\begin{array}{c}\text { Total } \\
\text { patients }\end{array}$ \\
\hline No of previous epidural anaesthetics given: & & \\
$<10$ & $13(2 \cdot 5)$ & 515 \\
$10-29$ & $20(2 \cdot 0)$ & 1014 \\
$30-59$ & $11(1 \cdot 4)$ & 794 \\
$60-89$ & $6(1 \cdot 2)$ & 505 \\
$\geqslant 90$ & $23(1 \cdot 3)$ & 1809 \\
No information & $1(1 \cdot 6)$ & 63 \\
Identification method: & & \\
Macintosh balloon & $26(2 \cdot 0)$ & 1333 \\
Loss of resistance/air & $38(1 \cdot 6)$ & 2308 \\
Loss of resistance/fluid & $8(0 \cdot 8)$ & 1043 \\
Other & & 14 \\
\hline
\end{tabular}

TABLE II-Long term symptoms in women with accidental dural puncture and in comparison groups. Figures are numbers (percentages) of women

\begin{tabular}{|c|c|c|c|}
\hline Long term symptoms & $\begin{array}{c}\text { Dural } \\
\text { puncture } \\
(n=74)\end{array}$ & $\begin{array}{c}\text { Epidural } \\
\text { anaesthetic, } \\
\text { no puncture } \\
(\mathrm{n}=4626)\end{array}$ & $\begin{array}{l}\text { No epidural } \\
\text { anaesthetic } \\
(n=6935)\end{array}$ \\
\hline Frequent headache or migraine ${ }^{\star}$ & $13(17 \cdot 6)$ & $251(5 \cdot 4) \dagger$ & $245(3.5)$ \\
\hline Neck ache & $8(10.8)$ & $108(2 \cdot 3) \dagger$ & $112(1 \cdot 6)$ \\
\hline Women with any of above symptoms & $17(23.0)$ & $329(7 \cdot 1) \dagger$ & $333(4 \cdot 8)$ \\
\hline Shoulder ache & $5(6 \cdot 8)$ & $121(2 \cdot 6)$ & $137(2 \cdot 0)$ \\
\hline Visual disturbances & $2(2 \cdot 7)$ & $80(1 \cdot 7)$ & $91(1 \cdot 3)$ \\
\hline Auditory symptoms & $1(1 \cdot 4)$ & $28(0 \cdot 6)$ & $46(0.7)$ \\
\hline
\end{tabular}

TABLE III-Duration, persistence, and medical consultation in each woman who reported long term symptoms after accidental dural puncture

\begin{tabular}{lcccc}
\hline Case No & $\begin{array}{c}\text { Duration of } \\
\text { symptom(s) } \\
\text { (weeks) }\end{array}$ & $\begin{array}{c}\text { Symptom(s) } \\
\text { still } \\
\text { present }\end{array}$ & $\begin{array}{c}\text { Consulted } \\
\text { doctor }\end{array}$ & $\begin{array}{c}\text { Had } \\
\text { treatment } \\
\text { from doctor }\end{array}$ \\
\hline 1 & 9 & No & No & - \\
2 & 13 & No & No data & No data \\
3 & 13 & No & No & - \\
4 & 26 & No & No & - \\
5 & 36 & No & Yes & Yes \\
6 & 52 & No & Yes & Yes \\
$7^{\star}$ & 65 & Intermittent & Yes & Yes \\
8 & 61 & Yes & Yes & Yes \\
$9 \dagger$ & 78 & Yes & No & - \\
10 & 82 & Intermittent & No & - \\
11 & 100 & Yes & Yes & Referred \\
12 & 104 & No & No & - \\
13 & 113 & Yes & No & - \\
$14 \ddagger$ & 278 & Yes & No & - \\
15 & 390 & Intermittent & Yes & Yes \\
16 & 412 & Yes & No data & No data \\
17 & 433 & Yes & Yes & Referred \\
\hline
\end{tabular}

All patients unless otherwise stated, had symptoms starting within the first week.

*Patient had accompanying auditory symptoms.

tHeadache started in week 3 but patient also reported neck ache and shoulder ache starting immediately and lasting four weeks.

$\ddagger$ Migraine-type headaches started in week 4 .

mentioned headache had reported neck ache with shoulder ache.

Although symptoms were defined as "long term" if they had lasted for more than six weeks, most had lasted much longer. Among the 17 women reporting headache or neck ache, $11(65 \%)$ had had these symptoms for over a year and 10 still had them at the time of questioning. In three cases the symptoms had resolved within three months, in one they had lasted for six months, and in two cases they had persisted between six months and a year. A further eight women reported headache after dural tap, which, though not defined as long term according to our criteria, persisted for three weeks in four cases, four weeks in three cases, and six weeks in one.

No information was obtained on the severity of symptoms, but the women were asked whether they had consulted a doctor and received treatment. Of the 17 women with headache or neck ache, seven had consulted, eight had not, and two did not answer. All seven who consulted said they received treatment, usually painkillers, and two were referred for specialist consultation.

\section{Discussion}

This study has shown that in a series of 74 cases of accidental dural puncture that occurred among 4700 women given an epidural anaesthetic, 17 women $(23 \%)$ reported one or more of headache or migraine or neck ache starting afterwards and lasting for more than six weeks. In 10 cases symptoms remained unresolved at the time of questioning 15 months to eight years later. These symptoms after accidental puncture are well known but generally regarded as short lived and self limiting. ${ }^{189}$ There have been some case reports of long term sequelae, 112 but we know of no systematic investigation of long term symptoms after accidental dural puncture.

Our information about symptoms lacked detail. As the study was part of a much larger investigation of a range of long term health problems after childbirth, we could not focus on details of particular symptoms. We inquired only which women had reported each symptom, when it had started, how long it had lasted, and whether the women had sought medical consultation or received treatment. We obtained no information on the specific nature of the headaches-that is, their characteristics or severity or frequency of occurrence. Some women noted on the questionnaire that their symptoms, although unresolved, were only inter- 
mittent (see table III). We need more information on symptom details.

Report bias must also be considered. Most women have headache at some time. We asked about "frequent headaches," but after a dural tap a woman's perception of the term might be influenced by events in the puerperium, particularly if she had experienced or been warned about the possibility of headache. Thus infrequent and mild headache might be overreported by this group. Response bias is also relevant. Although our estimated $78 \%$ response rate was high, nonrespondents were likely to include more of the women who had dural taps without subsequent problems. All forms of bias demand further investigation before causal inferences can be drawn.

Mechanisms to account for prolonged headache have been considered for spinal anaesthesia. Vandam and Dripps investigated long term symptoms after 10098 spinal anaesthetics and suggested that vascular changes may occur or that the headache, after being initiated by cerebrospinal fluid drainage, might be perpetuated by the stress of everyday life. ${ }^{16}$ Abouleish suggested that the dural tear might not repair adequately, with a resulting fistula and possible continuous leakage of cerebrospinal fluid, complicated subsequently by psychological, vascular, and muscular factors. ${ }^{17}$ The larger gauge needles used for epidural as compared with spinal anaesthesia might mean that inadequate or delayed repair is more likely.

Prolonged headache after accidental dural puncture was initially considered extremely unlikely. ${ }^{18}$ More recent case reports suggest that they might occasionally occur. ${ }^{12}$ Our study suggests that long term symptoms occur more often than this. The limited data on characteristics of the symptoms and the reliance on lengthy recall in our study demand an extremely cautious consideration of a possible causal relation but make it very clear that the topic requires further investigation.

Dr J Selwyn Crawford helped in initiating this research up to his death in August 1988. Thanks are due to the women who participated. The work was financed by a grant from the Department of Health. A copy of the questionnaire used in the survey may be obtained from $\mathrm{CM}$

1 Crawford JS. Lumbar epidural block in labour: a clinical analysis. $B r f$ Anaesth 1972;44:66-74

2 Crawford JS. The second thousand epidural blocks in an obstetric hospital practice. Br I Anaesth 1972;44:1277-87.

3 Brownridge P. A three-year survey of an obstetric epidural service with top-up doses administered by midwives. Anaesth Intensive Care 1982;10:298-308.

4 Ong B, Cohen MM, Cumming M, Palahniuk RJ. Obstetrical anaesthesia at Winnipeg Women's Hospital 1975-83: anaesthetic techniques and complications. Can $\mathcal{f}$ Anaesth 1987;34:294-9.

5 Okell RW. Unintentional dural puncture. A survey of recognition and management. Anaesthesia 1987;42:1110-3.

6 Reynolds F. Epidural analgesia in obstetrics: pros and cons for mother and baby. BMF 1989;299:751-2.

7 Kalas DB, Hehre FW. Continuous lumbar peridural anaesthesia in obstetrics: VIII. Further observations on inadvertent lumbar puncture. Anesth Analg 1972;51:192-5.

8 Brownridge P. The management of headache following accidental dural puncture in obstetric patients. Anaesth Intensive Care 1983;11:4-15.

9 Bromage PR. Epidural analgesia. Toronto: Saunders, 1978.

10 Stride PC, Cooper GM. Dural taps revisited. A 20 year survey from Birmingham Maternity Hospital. Anaesthesia 1993;48:247-55.

11 Cast W, Edlist G. Post spinal headache, successful epidural blood patch eleven weeks after onset. $\Im A M A$ 1974;227:786-7.

12 Scott DB, Hibbard BM. Serious non-fatal complications associated with extradural block in obstetric practice. Br $\mathcal{A}$ Anaesth 1990;64:537-41.

13 MacArthur C, Lewis M, Knox EG, Crawford JS. Epidural anaesthesia and long-term backache after childbirth. BMF 1990;301:9-12.

14 MacArthur C, Lewis M, Knox EG. Investigation of longterm problems after obstetric epidural anaesthesia. BMf 1992;304:1279-82.

15 MacArthur C, Lewis M, Knox EG. Health after childbirth London: HMSO, 1991

16 Vandam LD, Dripps RD. Long-term follow-up of patients who received 10098 spinal anaesthetics. Syndrome of decreased intracranial pressure (headache and ocular and auditory difficulties). $\mathscr{F} A M A$ 1956;161:586-91.

17 Abouleish E. Epidural blood patch for the treatment of chronic post-lumbarpuncture cephalgia. Anesthesiology 1978;49:291-2.

(Accepted 3 February 1993)

\title{
Factors affecting quality of informed consent
}

\author{
Christine Lavelle-Jones, Derek J Byrne, Peter Rice, Alfred Cuschieri
}

Departments of Surgery and Psychiatry, Ninewells Hospital and Medical School, University of Dundee, Dundee DD1 9SY Christine Lavelle-Jones, research assistant, department of surgery

Derek J Byrne, senior surgical registrar

Peter Rice, consultant psychiatrist Alfred Cuschieri, professor of surgery

\section{Correspondence to:}

Professor Cuschieri.

BMF 1993;306:885-90
Abstract

Objective-To examine the factors influencing quality of informed consent.

Design-Prospective study comprising interviews with patients and patients' completing standard qr:estionnaires.

Setting-Academic surgical unit of large teaching hospital.

Patients-265 patients undergoing intrathoracic, intraperitoneal, and vascular surgical procedures. Of these patients, 192 have been followed up for six months.

Main outcome measures-Patients' recall of information at various points in the study; this score was compared by age, provision of written information, cognitive function, intelligence quotient (IQ), mood state and personality traits, and health locus of control.

Results-The patients were best informed immediately after signing the consent form and from then on recall of information deteriorated. A total of $172 / 250(69 \%)$ patients admitted to not reading the consent form before signing it. Old age adversely affected recall of information at all assessment points. Impaired cognitive function reduced information recall only during the stay in hospital. Patients with above average IQs handled information better than those with a lower IQ except immediately after the signing of consent forms.
Patients with an internal locus of health control (that is, those who believed their health to be in their own control) were better informed than those with an external locus of health control. Operation information cards improved recall only on the day of discharge.

Conclusion-Elderly patients and patients with below average IQ, impaired cognitive functions, and an external locus of control have poor information recall. Written information may be more useful if given before admission to hospital.

\section{Introduction}

Informed consent is a legal requirement for all surgical procedures. Despite this a substantial number of patients are unaware of important details concerning their surgery. ${ }^{12} \mathrm{~A}$ few studies have reported on the effect of written as opposed to oral information on the quality of informed consent, ${ }^{23}$ but no investigation has assessed the relation of characteristics of individual patients to the appreciation and recall of specific information relating to treatment. Effective strategies to improve this may need to be different in various groups as understanding and recall of medical information may be influenced by age, intelligence quotient (IQ), cognitive function, and factors in the patient's mood or personality. We studied prospectively the effect of these variables on recall of medical informa- 